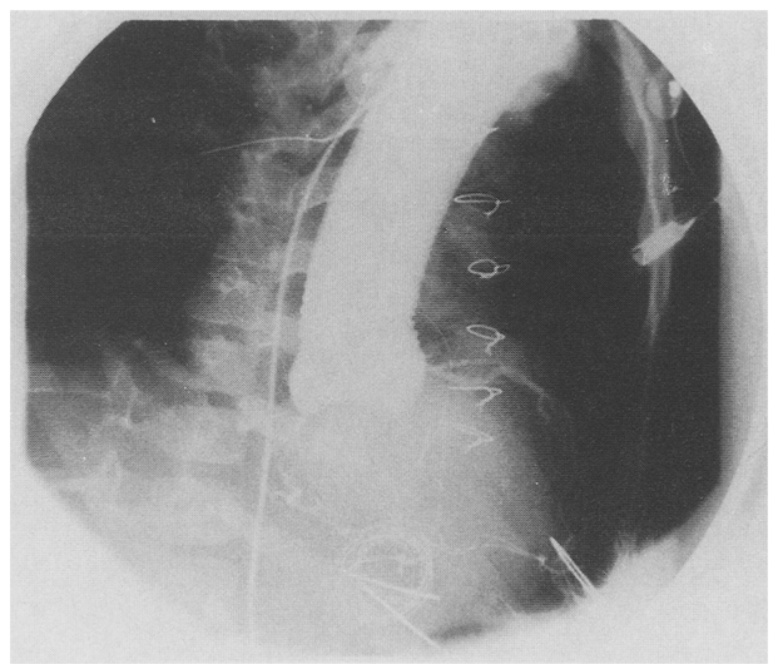

Fig. 2. Postoperative aortogram illustrated satisfactory repair of ascending aorta and aortic arch with good aortic valve competence.

arterial wall, ${ }^{1}$ and is associated with the highest prevalence of vascular complications, including multiple aneurysm formation and spontaneous rupture and dissection of large and small arteries. ${ }^{2,3}$ Increased risk of fatal intraoperative vascular complications has been largely indicated, ${ }^{3}$ and therefore special care in handling the fragile vessels of patients with EDS has been suggested. ${ }^{2,3}$ However, because the natural history of this disease is poor, ${ }^{2}$ surgical treatment should be considered in most instances. ${ }^{3,5}$

In our patient, the increasing size of the aneurysm, and therefore the high probability of aneurysmal rupture, repre- sented a clear indication for surgical repair despite the high risk of operative complications. Aortic valve replacement and coronary reimplantation were not necessary, inasmuch as the aneurysm did not involve the aortic anulus (Fig. 1). Unlike findings in patients with Marfan's syndrome, annuloaortic ectasia is rarely seen in patients with ascending aortic aneurysm as a result of EDS. ${ }^{5}$ Wide variation among patients with type IV EDS with respect to the degree of vascular involvement has been described, and cases include those of patients with partial or no weakness of the arterial wall. ${ }^{2,5}$ As confirmed by the histopathologic finding of partial collagen fiber heterogeneity, in the case reported herein the aortic tissue was only moderately friable, which allowed invasive diagnostic procedures and surgical repair to be done without complications. Our experience indicates that safe repair of thoracic aortic aneurysm is possible in children with EDS and that recognition of aortic wall peculiarities is helpful in determining the prognosis.

\section{REFERENCES}

1. Pope FM, Martin GR, Lichtenstein JR, et al. Patients with Ehlers-Danlos syndrome type IV lack type III collagen. Proc Natl Acad Sci 1975;72:1314-6.

2. Serry C, Agomuoh OS, Goldin MD. Review of Ehlers-Danlos syndrome: successful repair of rupture and dissection of abdominal aorta. J Cardiovasc Surg 1988;29:530-4.

3. Mattar SG, Kumar AG, Lumsden AB. Vascular complications in Ehlers-Danlos syndrome. Am Surg 1994;60:827-31.

4. Sarkar R, Coran AG, Cilley RE, Lindenauer SM, Stanley JC. Arterial aneurysms in children: clinicopathologic classification. J Vasc Surg 1991;13:47-57.

5. Raman J, Saldanha RF, Esmore DS, et al. The Bentall procedure: a surgical option in Ehlers-Danlos syndrome. J Cardiovasc Surg 1988;29:647-9.

\title{
MINIMALLY INVASIVE DIRECT CORONARY ARTERY BYPASS, PERCUTANEOUS TRANSLUMINAL CORONARY ANGIOPLASTY, AND STENT PLACEMENT FOR LEFT MAIN STENOSIS
}

\author{
William G. Liekweg, MD, ${ }^{\mathrm{a}}$ and Ramesh Misra, MD, ${ }^{\mathrm{b}}$ Flint, Mich.
}

Minimally invasive direct coronary artery bypass $(\mathrm{CAB})$ is rapidly gaining acceptance in the field of cardiac surgery. ${ }^{1}$ The advantages of decreased morbidity, shorter hospital stays, and recovery time are appealing to patients

From the Divisions of Cardiac Surgery ${ }^{\mathrm{a}}$ and Cardiology, ${ }^{\mathrm{b}}$ Genesys Regional Medical Center, Flint, Mich.

Received for publication July 22, 1996; accepted for publication Sept. 5, 1996.

Address for reprints: William G. Liekweg, MD, Cardiovascular and Thoracic Surgeons, PC, 302 Kensington Ave, Flint, MI 48503.

J Thorac Cardiovasc Surg 1997;113:411-2

Copyright (c) 1997 by Mosby-Year Book, Inc.

$0022-5223 / 97 \$ 5.00+0 \quad \mathbf{1 2 / 5 4 / 7 7 8 5 7}$ and surgeons. The indications and techniques for this procedure are being defined. ${ }^{2}$

This article demonstrates the utility of the minimally invasive direct $\mathrm{CAB}$ procedure as an adjuvant therapy to allow angioplasty and stent placement for left main stenosis.

A 52-year-old man underwent cardiac catheterization for progressive angina. The results revealed $90 \%$ stenosis of the left main coronary artery, mild disease of the right coronary artery ( $<30 \%$ stenosis), and moderately depressed ejection fraction (Fig. 1). This man had diabetes mellitus and chronic renal failure (creatinine $9 \mathrm{mg} / \mathrm{dl}$ ) for which he underwent peritoneal dialysis. He had chronic anemia (hemoglobin level $8.0 \mathrm{gm}$ ) but, being a devout Jehovah's Witness, refused all blood products. The initial 


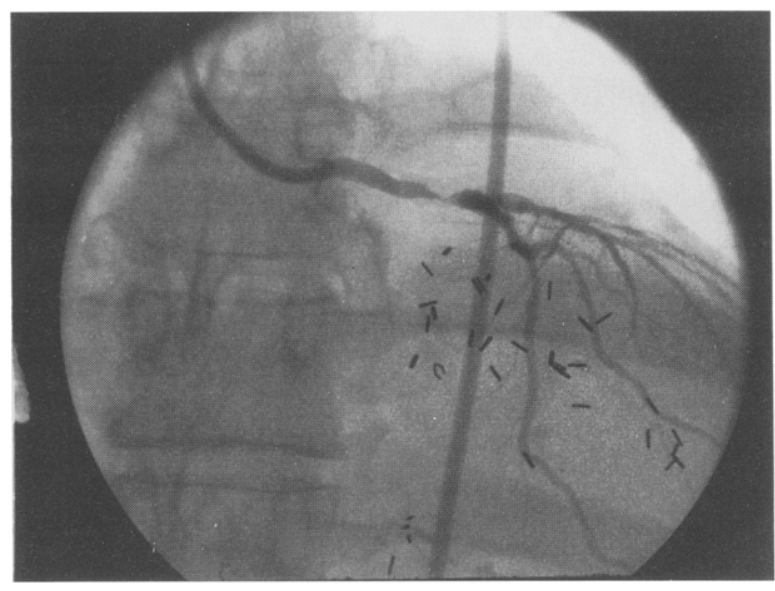

Fig. 1.

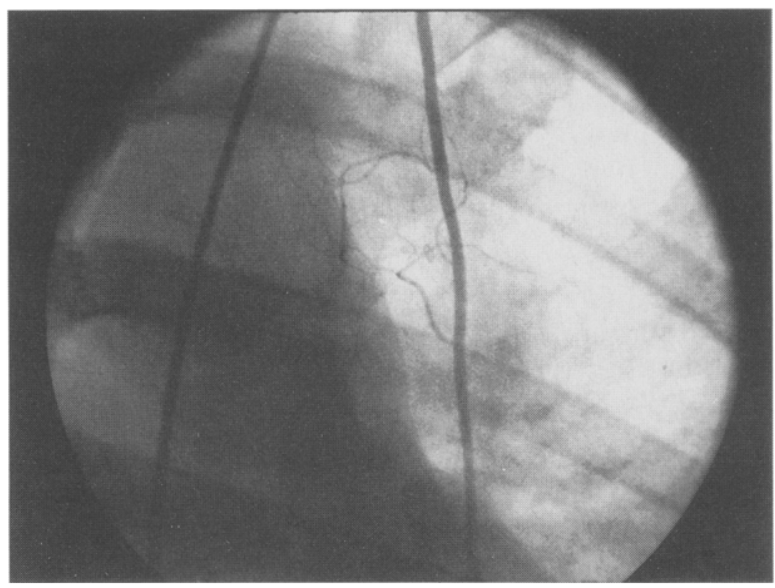

Fig. 2.

plan was to treat the anemia with epoetin alfa (Epogen) until the hemoglobin level reached $12.0 \mathrm{gm}$ and then proceed with conventional $\mathrm{CAB}$ grafting. However, he began to have accelerated angina necessitating a more urgent intervention.

At operation an $8 \mathrm{~cm}$ parasternal incision was made. The left fourth and fifth costal cartilages were removed. An $8 \mathrm{~cm}$ section of the internal thoracic artery (ITA) was dissected from the left side of the chest wall and anastomosed to the midportion of the left anterior descending coronary artery (LAD) with 7-0 Prolene sutures (Ethicon, Inc., Somerville, N.J.). Local blood flow was controlled with a $1.5 \mathrm{~mm}$ internal vessel occluder (Biovascular Inc., St. Paul, Minn.). Esmolol was given to slow the heart rate to 60 beats/min. A low dose of heparin (10,000 units) was administered and later reversed with a half dose of protamine. Flow in the ITA was measured at a rate of 100 $\mathrm{ml} / \mathrm{min}$. He was extubated a few hours after the operation and resumed his daily dialysis schedule. Total blood loss during the operation and the postoperative period was 110 $\mathrm{ml}$.

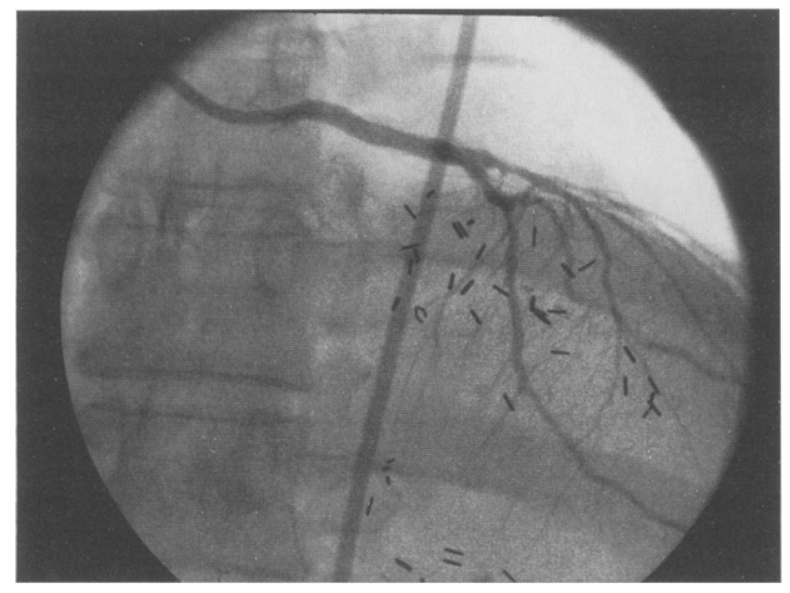

Fig. 3.

On the fourth postoperative day he was electively returned to the catheterization laboratory, where he underwent successful angioplasty of the left main coronary artery with a $3 \mathrm{~mm}$ Lifestream balloon (Applied Cardiac Systems, Inc., Temecula, Calif.) after patency of the ITA-LAD graft had been verified (Fig. 2). This was followed by placement of a $3.5 \mathrm{~mm}$ intracoronary stent (Johnson \& Johnson, Warren, N.J.) and final dilation with a $3.5 \mathrm{~mm}$ N.C. Bandit balloon (SciMed/Boston Scientific Corporation, Maple Grove, Minn.) (Fig. 3). Cardiopulmonary support standby was available but not used.

Innovative approaches to coronary disease may become more common now that minimally invasive direct $C A B$ has become technically feasible. Our patient had numerous medical problems that made standard CAB extremely risky. We believed that if the anterior wall could be protected by the ITA graft, angioplasty could be undertaken with less risk. We did not think that the ITA would provide sufficient long-term blood flow to both the LAD and circumflex systems in the event of left main closure.

The long-term state of the ITA graft to the LAD after reopening of the left main artery is unknown. It is suspected that significant competitive flow will lead to diminution in the ITA contribution to global blood flow. The "angiographic string sign" may develop, but this does not necessarily mean closure of the ITA.

The fact that the angioplasty proceeded with no hemodynamic changes or arrhythmias indicates that the ITA was protective during brief left main occlusion with balloon inflations. This might suggest that minimally invasive direct $\mathrm{CAB}$ may become a bridge to complete revascularization in conjunction with percutaneous intervention for multivessel coronary artery disease.

\section{REFERENCES}

1. Calafiore AM, DiDiammarco G, Teodore G, et al. Left anterior descending coronary artery grafting via left anterior small thoracotomy without cardiopulmonary bypass. Am Surg 1996;61:1658-65.

2. Arom KV, Emery RW, Nicoloff DM. Mini-sternotomy for coronary artery bypass grafting. Am Surg 1996;61:1271-2. 